\title{
'N NARRATIEWE BENADERING TOT DIE LITURGIE
}

Authors:

Lourens Bosman ${ }^{1,2}$

Julian Müller ${ }^{2}$

\section{Affiliations: \\ ${ }^{1}$ Nederduitse}

Gereformeerde Gemeente,

Lux Mundi, Pretoria,

Suid-Afrika

${ }^{2}$ Departement Praktiese

Teologie, Universiteit van

Pretoria, Suid-Afrika

Correspondence to:

Julian Müller

e-mail:

julian.muller@up.ac.za

\section{Postal address:}

Departement Praktiese

Teologie, Fakulteit Teologie,

Universiteit van Pretoria,

Pretoria, 0002, Suid-Afrika

\section{Keywords:}

Narratiewe; Liturgie:

aanbidding; vernuwing;

Evangelie

\section{Dates:}

Received: 18 Aug. 2008

Accepted: 25 Sept. 2009

Published: 27 Nov. 2009

How to cite this article: Bosman, L. \& Müller, J., 2009, 'n Narratiewe benadering tot die liturgie, Verbum et Ecclesia, 30(2) Art. $\# 179,6$ pages. DOI: $10.4102 /$ ve.v30i2.179

\section{This article is available} at:

http://www.ve.org.za

\section{Note:}

Hierdie artikel word ook in Engels en verwerkte vorm vir die Festschrift ter viering van Malan Nel se 70ste verjaarsdag aangebied.

(C) 2009. The Authors. Licensee: OpenJournals Publishing. This work is licensed under the

Creative Commons

Attribution License.

\section{ABSTRACT \\ A narrative approach to liturgy}

The fact that current liturgical renewal is not based on sound theological reflection, is cause for concern. A narrative approach to liturgy is therefore proposed, which would allow a better connection between the cultural story on the one hand, and the story of the gospel and the liturgical tradition on the other. The article therefore explores possibilities for a narrative understanding of the liturgical context, and shows how a worship liturgy could be created like a collage instead of in the form of linear argumentation.

\section{INLEIDING}

\section{Liturgie - waarom DIT narratief benader?}

In die Protestantse kerklike praktyk in Suid-Afrika vind daar tans baie verandering en soms vernuwing op die gebied van die liturgie plaas. Vernuwing in die liturgie is verblydend, maar ongelukkig blyk dit of baie van hierdie vernuwing sonder teologiese oordenking plaasvind, en eerder deur die charismatiese 'praise and worship'-beweging gerig word. Hierdie artikel wil graag ' $n$ bydrae lewer tot tersaaklike oordenking vanuit ' $n$ postmoderne hoek. Die vraag is: Op watter manier hou ons, te midde van vernuwing, vas aan die identiteit van die erediens as 'n uitlewing van die Joods-Christelike tradisie van aanbidding? Om hierdie oordenking so tersaaklik en teologies verantwoordbaar moontlik te maak, ontgin hierdie artikel die moontlikhede van 'n narratiewe benadering tot die liturgie.

'n Narratiewe begrip van die liturgie behels onder andere die volgende:

- Liturgie is ' $n$ voortgaande proses van verhaaloordrag en -ontwikkeling.

- Liturgie kan as 'n oorvertelling van ' $n$ bekende verhaal beskou word.

- Liturgie behels ook die voortdurende opbou van 'n nuwe begrip van die bekende verhaal.

- Liturgie is 'telling a past and dreaming a future' (Brueggemann 1989).

- Net soos alle aspekte van kerkwees, speel liturgie te midde van die dinamiek tussen dominante en gemarginaliseerde verhale af.

- Liturgie is ' $n$ dramatiese vertelling wat simboliese en verbale kommunikasie integreer.

Dié artikel het as uitgangspunt dat die verhale wat mense van hulleself vertel, aan hulleself vorm gee en ook weerspieël wat hulle oor hulleself glo. Hierdie verhale wat mense oor hulleself vertel, word egter nie outonoom deur elke individu gekonstrueer nie. Verhale word ook aan ons gegee; mense ontvang verhale, wat dan vorm gee aan die wyse waarop hulle hulle eie verhale skryf, en aan dít wat hulle uiteindelik oor hulleself glo. In hierdie verband ís al aangetoon watter groot invloed sprokies (synde sulke verhale wat ontvang word) het op die manier waarop kinders, en later ook volwasse mans en vroue, hulle eie verhale skryf - die dinge wat hulle as sukses en mislukkings beleef; hoe hulle hulle eie lewens aan die norm meet van die verhale wat hulle kleintyd herhaaldelik gehoor het. Ongelukkig is hierdie meesterverhale nie altyd goed vir mense nie. Dit plaas hulle dikwels in rolle waar ander hulle domineer; waar hulle nie hulle eie waarde kan raaksien nie, en waarin die waardes van sukses en 'n goeie lewe nie met die waardes van die Evangelie strook nie.

Dit is egter nie net die inhoud van dié gegewe verhale wat ' $\mathrm{n}$ groot vormende invloed het op die manier waarop mense hulle eie verhale skryf en beoordeel nie, maar ook die struktuur van die verhale. Narratoloë wys daarop dat daar in elke kultuur ' $n$ aantal meesternarratiewe bestaan waarvolgens die meeste groot stories geskryf is: Heldeverhale, tragedies, die verhaal van die groot reis, en die verhaal van die held wat die skoonheid red, is 'n paar voorbeelde. Hierdie meesterverhale word ook soms 'diskoerse' genoem. Freedman en Combs (1996:42) gebruik Hare-Mustin se omskrywing, wat sê: 'A discourse is a system of statements, practices, and institutional structures that share common values.' Dié outeurs wys verder daarop dat die manier waarop die meeste mense ' $n$ sekere gedeelde standpunt huldig, dit bespreek en op grond daarvan handel, 'n manier is om sulke diskoerse in stand te hou en te laat voortbestaan. In ' $n$ bepaalde kultuur sal mense intuïtief hulle eie verhale aan die hand van hierdie meesterverhale konstrueer.

In hierdie verband wil die narratiewe benadering tot terapie (sien Müller 2000) mense help om bewus te raak, en sodoende bevry te raak, van hierdie een dominante verhaal of diskoers wat hulle lewens oorheers. Só word hulle gehelp om tot 'n deegliker en ryker begrip van hulleself te kom. Dít word gedoen deur eers die dominante verhaal of verhale uit te wys, en te kyk na die maniere waarop dit negatief op die persoon se self- en wêreldbeskouing inwerk. Daarna soek die terapeut en die gespreksgenoot saam na alternatiewe verhale wat laasgenoemde help om sy/haar eie verhaal op so ' $n$ manier te herskryf dat dit hom/haar vorentoe sal help.

Hoe hou dít alles egter verband met die liturgie? Die liturgie is een van die heel sterkste vormende invloede op die manier waarop erediensgangers hulle geloofsverhale konstrueer. Die herhalende aard van die liturgie gee aan mense ' $n$ duidelike vorm waarin hulle hulle eie geloofsverhale giet. So sal 'n liturgie waarin mense elke Sondag van voor af gered moet word deur na die wet te luister, hulle skuld te besef en te bely, en daarna vrygespreek te word, 'n bepaalde invloed hê op die manier waarop hulle hulle verhouding met God én hulleself sal beskou, en hoe hulle hulle geloofsverhale sal konstrueer. 
Dit kan egter ' $n$ probleem wees wanneer slegs een of twee verhale die liturgie domineer. Dit verskraal die ryke verskeidenheid van meesterverhale van die verhouding tussen God en die mens wat in die Bybel te vinde is, en hou nie rekening met die groot verskeidenheid verwagtings en ervarings waarmee mense na die erediens kom nie. Daarom is 'n verskeidenheid liturgiese verhale nodig om die erediensgangers te help om die rykdom van ervarings van die menslike staat, met die ervaring van die teenwoordigheid van God in die erediens, en daarna ook in hulle lewens, in verband te bring.

Die liturgie is die samevloeiing en konsentrasiepunt van 'n verskeidenheid verhale. Hierdie artikel poog om dié verskeidenheid verhale aan die hand van drie liturgiese perspektiewe te beskou, wat telkens vanuit 'n narratiewe hoek benader sal word:

- Die liturgiese handeling as deel van 'n groter verhaal

- Die verhalende verloop van die liturgie

- Die verhalende inhoud van die liturgie

\section{DIE LITURGIESE HANDELING AS DEEL VAN 'N GROTER VERHAAL}

Gibbs en Bolger (2006:70-71) dui twee groot verskuiwings aan wat tussen die moderne en postmoderne era ten opsigte van inligtingsoordrag plaasgevind het. Eerstens is daar die verskuiwing weg van die lineêre oordrag van abstrakte, proporsionele waarhede, na konkrete, veelvlakkige narratiewe met veelvuldige betekenisse. Voorts is daar ook die verskuiwing weg van die enkelvoudige klem op die gehoor, na die dominansie van visuele kommunikasie. Die erediens vind deesdae in 'n visuele en verhaalgegronde kultuur plaas.

Hierdie ontwikkelinge bied opwindende moontlikhede vir ' $\mathrm{n}$ nuwe benadering tot die liturgie. Die liturgie, wat ' $\mathrm{n}$ simboliese versameling van 'n verskeidenheid verhale is, hoef nie noodwendig lineêr-logies te ontwikkel nie. Dit bied juis die moontlikheid van veelvlakkige, narratiewe kommunikasie.

Die blote feit dat menslike handelinge 'vertelbaar' is, is te danke daaraan dat dit reeds betekenis het wat in 'n bepaalde kultuur daaraan toegeken word:

If, in fact, human action can be narrated, it is because it is always already articulated by signs, rules, and norms. It is always already symbolically mediated.

(Ricoeur 1984:58).

Liturgie is niks anders as simboliese vormgewing aan die verhale van mense nie, maar in besonder die verhaal van God en die mens. Ricoeur (1984) stem ook hiermee saam:

A symbolic system thus furnishes a descriptive context for particular actions. In other words, it is "as a function of" such a symbolic convention that we can interpret this gesture as meaning this or meaning that.

(Ricoeur 1984:59)

In die erediens is sekere handelinge reeds met betekenis gelaai; dit het rituele funksie, en maak gesamentlik die liturgie uit.

\section{DIE VERHALENDE VERLOOP VAN DIE LITURGIE}

Ricoeur (1984:54) se driedeling (sien Demazure \& Müller 2006:410-413) van hoe 'n mens deur 'n teks lees, en dit jou tot nuwe begrip en optrede bring, is nuttig om te verstaan wat met erediensgangers kan gebeur wanneer die liturgie hulle as deelnemers betrek. Hierdie drieledige proses:

- begin met 'n voorafgaande voorstelling (oftewel prefigurasie) waarmee die leser die teks benader;

- gaan dan oor tot die skep van gelykvormighede en begrip (oftewel konfigurasie) wanneer die leser deur die teks lees waarin die gebeure in 'n samehangende geheel saamgevoeg word, en die teks só betekenis kry (Ricoeur 1984:67); en
- lei uiteindelik tot nuwe betekenis of sin (oftewel refigurasie) wanneer die leser deur die lees van die teks tot ' $n$ nuwe self- en werklikheidsontdekking kom. Dit verwys dus na 'n proses van transformasie by die leser as gevolg van sy/haar ontmoeting met die karakters en gebeure van die verhaal.

Dit is belangrik dat dit vir Ricoeur nie bloot oor nuwe begrip gaan nie, maar ook oor nuwe optrede in die werklikheid; refigurasie lei immers terug na die wêreld en na handelinge.

Die postmoderne mens is geskool in, en geniet, 'n sirkulêre, speelse, paradoksale en nimmereindigende proses van allegoriese voorstelling, oftewel 'figurasie'. Dít maak die hedendaagse liturgie uitdagend, maar open terselfdertyd etlike deure van verbeelding en vormgewing.

Kearney (1998) verduidelik dat die paradigmaskuif van premodern tot postmodern aan die hand van drie metafore beskryf kan word. Waar die premoderne paradigma deur 'n enkele spieël verteenwoordig kan word (wat die lig uit 'n transendente oorsprong weerkaats), kan die moderne paradigma weer as 'n lamp beskou word (wat ' $n$ oorspronklike lig van binne homself projekteer). Die postmoderne paradigma kan die beste beskryf word as ' $\mathrm{n}$ hele reeks spieëls wat mekaar weerkaats:

The postmodern paradigm is, in other words, that of a labyrinth of mirrors which extend infinitely in all directions - a labyrinth where the image of the self (as a presence to itself) dissolves into self-parody.

(Kearney 1998:253)

Hierdie parodie, of speelse weerkaatsings van die werklikheid en die self, word die kenmerk van postmodernisme. Die mense wat Sondae in die kerk sit, is behoorlik geskool in hierdie paradigma. Hulle word daarin ingelyf deur hulle blootstelling aan die teater, skilderkuns en letterkunde. In hierdie verband sê Kearney (1998) ook: 'The parodic paradigm recurs time and again in postmodern works of art and literature' (Kearney 1998:253). Die vraag is nou: Wat is die liturgiese reaksie op hierdie werklikheid?

As die lineêr-logiese benadering tot die liturgie met 'n sirkulêre collage-benadering vervang kan word, sal die postmoderne mens waarskynlik beter aanklank daarby vind. Hierdie stelling moet egter nie misverstaan word nie. Met collage word nie ' $n$ arbitrêre sameflansing van ' $\mathrm{n}$ aantal items bedoel nie, maar eerder ' $\mathrm{n}$ ander manier van plotontwikkeling en -vormgewing.

In die roman The Crossing, die tweede deel van Cormac McCarthy se Border Trilogy (1994), verduidelik 'n verloopte priester dat verhale vorm gee aan die ervarings en gebeure van die werklikheid. Die priester stel dit só:

Things separate from their stories have no meaning. They are only shapes. Of a certain size and color. A certain weight. When their meaning has become lost to us they no longer even have name. The story on the other hand can never be lost from its place in the world, for it is that place.

(McCarthy 1994:n.p.)

Voordat gebeure en ervarings nie in 'n plot samehang vind nie, het dit geen betekenis nie. Die verhaal waarin dit gegiet word, verleen daaraan betekenis en plek. Daarom praat Ricoeur (1984:66) dan ook van 'emplotment' as 'a synthesis of the heterogeneous'. Die skrywer of verteller bring heterogene gebeure, ervarings, simbole, vertellings, liedere en gedigte in ' $\mathrm{n}$ plot byeen waarin dié dele gesamentlik meer beteken as afsonderlik: 'Plotting is an activity in which temporal happenings are shaped into meaningful units' (Polkinghorne 1988:160).

In ' $\mathrm{n}$ oordenking oor liturgie as verhaal, bepaald vir die postmoderne era waarin eredienste tans gestalte kry, moet ten minste twee oënskynlik teenstellende aspekte van postmoderne narratiewe van nader bekyk word. Aan die een kant geld die narratiewe beginsel steeds dat plot nie iets arbitrêr is nie. Die liturg kan nie sommer enige klomp gebeure of vertellings saamgooi, sonder om te vra hoe dit bymekaar hoort nie. 'n Goeie 
plot het ' $n$ bepaalde interne logika. Die plot help om die gebeure in ' $n$ besondere samehang te plaas wat in sy geheel groter is as die individuele gebeure. Waarde word as't ware tot die individuele gebeure toegevoeg; elkeen se afsonderlike betekenis word ryker, meer genuanseerd, deur die samehang waarin dit geplaas word.

Daarom is die plot van 'n liturgie nie arbitrêr nie. In 'n narratiewe begrip van die liturgie moet liturgieë by die verband pas waarin die erediens plaasvind, maar moet dit ook getrou wees aan die groot Joods-Christelike tradisie waarvan dit deel uitmaak. Uit ' $n$ postmoderne hoek word die verband van die erediens beter aangevul deur liturgieë wat na die groot verhale uit die Joods-Christelike tradisie teruggryp, as wanneer die liturgieë op die sistematiserings geskoei is van die moderne projek om die algemene/universele waarhede van die Christendom tot logies samehangende dog kille en onpersoonlike, leerstellige uiteensettings van die inhoud van die Bybel te reduseer (sien Brueggemann 1989:1-2). Die doel is ervaringsgetroue, lewensegte, gebeurlike verhale waarin die erediensgangers hulle eie ervarings en lewens kan herken. Hierdie soort verhaalvorme is veel eerder in die groot narratiewe van die Bybel as in die dogmatiek te vinde.

Die tweede aspek van postmoderne narratiewe is die konsep van 'collage' of 'montage' as kenmerkende postmoderne mediums. Collage is ' $n$ styl wat dikwels in postmoderne kuns, letterkunde, argitektuur en stadsbeplanning gebruik word (Harvey 1990:40,48,51; Scheepers 1998:30). Harvey (1990) verwys ook na Derrida, wat collage of montage as die hoofvorm van postmoderne diskoers beskou het waarin betekenis vloeibaar en toevallig is:

The inherent heterogeneity of that (i.e. collage), (be it in painting, writing, architecture) stimulates us, the receivers of the text or image, 'to produce a signification which could be neither univocal nor stable'. Both producers and consumers of 'texts' (cultural artifacts) participate in the production of significations and meanings...

(Harvey 1990:51)

Die gebruik van collage of montage hang saam met die versplinterde werklikheid, wat' $n$ hoofmotief in die postmoderne samelewing is (Harvey 1990:54). 'n Collage bestaan uit verskillende prente, motiewe en style wat in 'n kunswerk opgeneem word, en wat gesamentlik die kunswerk uitmaak. In postmoderne narratiewe tekste is daar ' $n$ eklektiese vermenging van style, verhale en brokstukke van verhale, wat in 'n enkele verhaal saamgevoeg word (Scheepers 1998:30).

Die idee van liturgie as ' $n$ postmoderne narratief met die kenmerke van 'n collage, laat ruimte vir ' $n$ verskeidenheid perspektiewe, liturgiese handelinge, simbole en verhale wat in ' $n$ plot saamgevoeg word. In 'n collage pas alles nie presies en eenduidig op ' $n$ bepaalde plek nie, en daarom is dit meer lewensgetrou vir postmoderne mense, wat in ' $n$ versplinterde werklikheid leef. Tog is daar ook samehang en voortgang in die liturgiese plot, al is dit nie voor die hand liggend nie. ' $n$ Liturgie as narratief met kenmerke van ' $\mathrm{n}$ collage, nooi die erediensgangers om aan die konfigurasie van die verhaal deel te neem, en skep daarom ook moontlikhede vir die refigurasie van hulle eie lewensverhale.

\section{DIE VERHALENDE INHOUD VAN DIE LITURGIE}

Hoe moet daar egter, met voormelde in gedagte, te werk gegaan word om ' $n$ liturgie van so ' $n$ verhalende aard te skryf? Anne Lamott se model vir fiksieskryf is in hierdie verband 'n nuttige struktuur aan die hand waarvan ' $\mathrm{n}$ hedendaagse moderne liturgie ontwikkel kan word. In haar boek oor die skryf van fiksie, Bird by Bird, ontwikkel sy die ABDCE- ('action, background, development, climax, ending'-) model. Dit kan as grondslag dien waarop die liturgie telkens weer beslag kan kry.

\begin{abstract}
Aksie ('action')
Aksie verwys na die huidige, aktuele verband: die dinge wat in die gemeenskap aan die gang is en waarmee mense hulle besig hou; sake waaroor gepraat en in koerante en tydskrifte geskryf word. Dikwels word hierdie aksie in die kulturele uitinge van ' $n$ gemeenskap bespeur. Waaroor handel die rolprente, en wat is die temas van die jongste boeke en teateropvoerings? Die aksie kan iets in die gemeentelewe, die kerkjaar, die gemeenskap of die nuus wees. Dit kan huidige debatte wees oor kernsake van die Evangelie, oor verdeeldheid in die kerk, oor hoe ons mekaar ten spyte van verskille probeer verdra, of oor die gemeenskap se moeite om die misdaadsituasie doeltreffend dog Christelik te hanteer.
\end{abstract}

Liturgie is nie veronderstel om tydloos te wees nie, maar juis tydgebonde en getrou aan ' $n$ baie bepaalde verband.

Dit is juis hierdie behoefte aan verankering in ' $n$ bepaalde verband wat tot weerstand teen eredienste in antieke tale soos Latyn gelei het.

\section{Agtergrond ('background')}

Elke aksie speel af teen ' $n$ agtergrond. Dinge gebeur nie maar net nie; daar is ' $n$ aanloopstorie. Die liturgie verteenwoordig nie net 'n aktuele verband nie, maar is ook veronderstel om 'n eeue-oue geloof en die teologie van die tradisie te vergestalt.

Lamott gebruik die beeld van die 'ontwerper' van ' $n$ toneelstuk, rolprent of verhaal:

It may help you to know what the room (or ship or the office or the meadow) looks like where the action will take place. You want to know its feel, its temperature, its colors. Just as everyone is a walking advertisement for who he or she is, so every room is a little showcase of its occupants' values and personalities.

Lamott (1995:74)

Koos du Plessis se Kerslied, Welkom, o stille nag van vrede (NG Kerk 2001), verwoord die agtergrond waarteen ' $n$ 'Somerkersfees' vorm aanneem op onverbeterlike wyse met die volgende woorde in die tweede vers: 'Hoor jy hoe sag die klokke beier in eeue-oue taal' (NG Kerk 2001:358).

Die liturgie moet dié 'eeue-oue taal' verklank, en dít maak die agtergrond of dekor uit waarteen ' $n$ hedendaagse drama moet afspeel.

\section{Ontwikkeling ('development')}

Hier gebruik Lamott (1995:39) die wonderlike beeld van die Polaroid. Hoewel die digitale geslag dalk nie dié beeld sal verstaan nie, bly dit ' $n$ besonder raak beskrywing vir dié wat nog kan onthou hoe die Polaroidkamera se foto voor jou oë uit die dofgrys papier verskyn.

Liturgie poog om twee wêrelde op so 'n manier bymekaar te bring dat verhaalontwikkeling plaasvind. Die ou verhaal van kerklike tradisie en geloofsbelydenis word by ' $n$ aktuele verband ingeweef om 'n nuwe borduurwerk te skep.

Wanneer liturgieë ontwikkel word waarin vorige sowel as huidige verbande ten volle verreken word, en iets aktueels kom tot stand, behoort ' $n$ verskeidenheid verhale en verhaalvorme liturgies gestalte te kry. Hier onder volg drie kort besinnings wat kan help om deegliker en ryker beskrywings van die lewe voor God in die liturgie te ontwikkel.

\section{Die evangelies en die verhaal van Jesus as grondslag vir die liturgie}

Van die sterkste en aanhoudendste kritiek op die gereformeerde eredienste wat in die afgelope dekades na vore getree het, was die manier hoe dit erediensgangers week ná week met skuld belaai het. Die prediking het sonder twyfel hierin ' $n$ rol gespeel, 
maar die liturgie waarin 'n mens jou elke week weer diep moes neerbuig voor die hoë reg, het ook ' $n$ aandeel hieraan gehad. Die tradisionele gereformeerde liturgie verwoord ongetwyfeld 'n geldige verhaal wat sy plek het, maar is waarskynlik sterk deur ' $n$ Pauliniese begrip van die Evangelie oorheers, wat verder deur die Augustiniaanse erfsondeleer versterk is. ' $n$ Beter aanwending van die evangelies, met die verhaal van Jesus wat uit verskillende hoeke vertel word, is moontlik ' $n$ ryke skat vir die liturgie wat nog onontgin lê. Vervolgens word die ontstaansgeskiedenis van die evangelies (veral aan die hand van Armstrong 2007 en Spong 2007) met 'n kontemporêre film, As it is in Heaven, in gesprek gebring.

Volgens die mees onlangse datering, is die drie sinoptiese evangelies (dit wil sê, dié met dieselfde siening) in die 20 jaar tussen 70 en $90 \mathrm{nC}$ geskryf - ongeveer 40 jaar ná die kruisiging, en nadat die briewe van Paulus (sedert ongeveer $52 \mathrm{nC}$ ) die lig gesien het.

- Volgens Bybelwetenskaplikes het die boek Markus teen ongeveer $70 \mathrm{nC}$ die lig gesien. Die jaar 70 was toe die tempel van Jerusalem verwoes is. Vanaf 66 tot $73 \mathrm{nC}$ het die Jode in ' $n$ ongelukkige verloorstryd teen die Romeinse owerheid betrokke geraak. Die laagtepunt vir die Jode was toe die Romeinse legioene onder leiding van Titus in $70 \mathrm{nC}$ die stad Jerusalem ingeneem het, en die heilige tempel met die grond gelykgemaak het. Dit moes vir die Jode en die vroeë Christene 'n ontsettende verlies gewees het - byna iets soos die 9/11-gebeure in New York. Hoewel die Christene hulle reeds duidelik afsonderlik van die Judaïsme georganiseer het, is daar ook aanduidings dat hulle nog baie nou verbonde gevoel het aan die sinagoge en die tempel. Hulle het hulleself as 'die ware Israel' beskou.

- Met die tempel wat verwoes en die Jode wat verneder is, word die Markus-evangelie geskryf om die lesers daaraan te herinner dat hulle op die God van Eksodus moet vertrou - die God wat redding bewerk te midde van die grootste nood. $\mathrm{Al}$ is die tempel verwoes en al is Jesus gekruisig, maak God weer' $n$ nuwe begin. Daarom word die grootste deel van die Markus-evangelie aan die lyding en kruisdood van Jesus gewy. Markus is in wese ' $n$ uitgebreide kruisigingsverhaal, en só word die kruisboodskap as God se Woord in die donkerste uur aangebied - 'n boodskap van hoop en nuwe lewe, wat juis uit die diepste vernedering spruit. Jesus is die eintlike tempel wat verwoes is en weer in drie dae opgebou is. Daar ís hoop.

' $n$ Dekade of twee later is die verwoesting van die tempel egter nie meer die oorheersende motief nie. Nou begin vrae oor die toekoms van hierdie nuwe, groeiende Jesusbeweging sterker na vore tree. Die Evangelie van Jesus het immers intussen, veral onder leiding van Paulus, ' $n$ wêreldbeweging geword, en daar was steeds verskille oor of dit hoofsaaklik Joods moes ontwikkel, en of die boodskap ook op die nie-Jode gerig moes word.

Nou skryf Matteus en Lukas hulle evangelies. Tien tot 15 jaar ná die verwoesting van die tempel, beskik hulle oor Markus se weergawe. Dit word gereeld in die sinagoge gelees, maar hulle het behoefte aan iets meer. Waarheen nou? Is die Evangelie van Jesus vir 'n spesiale klein groepie - die ware Israel - of moet hulle anders daaroor dink? Dit is interessant dat albei dit nodig vind om iets vooraan die Markus-evangelie te las. Van hoofstuk 13 af volg Matteus grootliks die Markusteks, en van hoofstuk 8 af doen Lukas dit ook. Hulle las egter die geboorteverhale vooraan. As dit nie vir hulle was nie, het ons nie ' $n$ Kersevangelie gehad nie. As deel van die geboorteverhale, gee albei ook ' $n$ geslagsregister.

Matteus veranker syne baie duidelik in die Joodse tradisie, met 'n geslagsregister wat by Abraham begin.

Lukas begin syne nie by Abraham nie, maar by Adam.

Matteus beklemtoon Jesus se Joodsheid, terwyl Lukas sy mensheid beklemtoon. Matteus sê dat net soos die Jode uit die
Egiptiese slawerny verlos is, so is die kindjie Jesus ook uit Egipte teruggebring om in Galilea en Nasaret sy taak te vervul. Lukas sê Jesus is ' $n$ kind van Adam, en plaas sy geboorte onmiddellik in die groter verband van keiser Augustus. Dit is ook Lukas wat die verhaal vertel van die tien melaatses wat genees is, en dan meld dat slegs een van die tien dankbaar teruggekom het - hy was 'n Samaritaan. Lukas vertel ook die gelykenis van die barmhartige Samaritaan. Matteus bied die Joodse aksent; Lukas bied die universele aksent. Tog doen albei ook moeite om die ander kant te beklemtoon. Dit is juis Matteus wat die verhaal van die wyses uit die Ooste en die ster insluit - dinge wat Jesus in die groter wêreld plaas. Lukas doen weer moeite om die verhaal van Jesus se besnydenis en sy besoek aan die tempel op 12-jarige ouderdom in te sluit.

Dit blyk dus dat albei, sowel Matteus as Lukas, hoewel op verskillende maniere, dieselfde twee dinge beklemtoon: Die Jesusverhaal is in die Joodse tradisie veranker, en Jesus is nie die Jode se eiendom nie, maar is vir 'die mense in wie Hy ' $n$ welbehae het' (Luk 2:14).

Aan die hand van voormelde, kan die drie sinoptiese evangelies dus soos volg met die film As it is in Heaven vergelyk word:

Markus wys vir ons dat die krisis juis die saad word waaruit die nuwe tot stand kom. Uit die donkerte van die kruis kom die nuwe lewe. Die uitkoms is daar waar jy dit die minste verwag. In $A s$ it is in Heaven word die kombinasie van die armsalige dorpie, die sukkelende kerkkoor met selfs 'n erg gestremde lid, en die ongeneeslike siekte van 'n dirigent sonder sy orkes, die kweekplek van nuwe hoop.

Matteus leer ons dat die antwoord in die bekende boodskap te vinde is - nêrens anders nie. Die verhaal van God met Abraham, Isak en Jakob voorsien die antwoord op al die vrae. Ons hoef nie op vreemde plekke te gaan soek nie. In As it is in Heaven is die kerk wél moedeloos en vasgeloop met 'n skynheilige predikant, maar vind die ontknoping nie sonder en buite die kerklike strukture plaas nie. Die koor wat die unieke uitkoms bied, is steeds deel van die gemeente.

Lukas se boodskap is dat ' $n$ nuwe begin nooit kan plaasvind as daar net na binne gekyk word en bekrompe aan die bestaande vasgeklou word nie. Die vreemdeling moenie net ontvang word nie, maar moet as die gestuurde van God beskou word wat die sleutel tot die oplossing en vernuwing dra. Hou in gedagte dat dit juis Lukas is wat die Emmaus-verhaal vertel, waar die Here Jesus as 'n doodgewone vreemdeling met die Emmaus-gangers kom saamloop. Eers as hulle hom innooi en toelaat om gasheer in hulle eie huis te speel, kom die ontknoping. Dit is presies soos dit ook in die film gebeur.

- Met Markus gee ons nie moed op nie, want in die verleentheid is die geleentheid; in die kruis is die opstanding.

- Met Matteus vind ons die gerusstelling dat ons deel het aan die ou Verhaal, en nie paniekerig na nuwe antwoorde hoef te soek nie.

- Met Lukas ontdek ons dat die Evangelie van Jesus nie net via ons eie begripstradisie na ons toe kom nie, maar soms juis verrassend, soos ' $n$ vreemdeling, van buite af. Is ons ontvanklik daarvoor?

Op grond van hierdie drie sinoptiese evangelies sou 'n mens dus drie verhalende liturgieë kon ontwikkel wat die boodskap van hoop in 'n tyd waarin die tempel by wyse van spreke verwoes lê, weer nuut kan verwoord. Dít sou gedoen kon word deur grepe (verhale) uit 'n evangelie voor te lees, en dit met liedere, gebede en simboliese handelinge aan te vul. ' $n$ Mens sou ook die snitte en musiek van As it is in Heaven baie treffend kon gebruik.

Hoekom is ek hier?

Net soos die prediking, kan die liturgie mense help om die groot vrae van die lewe te verwoord en te beantwoord. In hierdie verband is dit uiters belangrik om te verreken wat die groot vrae 
is waarmee mense deesdae na die erediens toe kom. Daar is ál meer eenstemmigheid dat die groot vraag nie meer is 'Hoe kan ek gered word?' nie, maar eerder 'Hoe kan ek sinvol leef?' en 'Hoekom is ek hier op aarde?'.

Een van die maniere waarop hierdie groot vraag liturgies hanteer kan word, is aan die hand van die meesterverhale van roeping. Die roepingsverhale in die Bybel het tipies die volgende elemente (Burger 2005:35):

- 'n Bewustheid van God se teenwoordigheid

- Skok wanneer die persoon van die grootsheid en heiligheid van God bewus word

- Troos wanneer God sy genade en liefde openbaar

- Roeping wanneer God 'n opdrag gee. Hierdie ervaring lok gewoonlik die volgende bepaalde reaksies uit:

- 'n Gevoel van onvermoë of selfs onwilligheid

- God wat volhou met sy roeping

- Die individu wat toegee en die roeping aanvaar

\section{Moet ons tog nie aan ons lot oorlaat nie!}

In Suid-Afrikaanse verband, met hoë misdaadvlakke, kom geloofsgemeenskappe deesdae soms na die erediens met 'n verenigde belewing van pyn en radeloosheid. Dit sou tipies met gebeure in die nuus of bepaald in die gemeenskap saamhang. Die verenigde klaagpsalms kan help om 'n liturgie te skryf wat hierdie gemeenskaplike klag in ' $n$ verhaal laat afspeel. Westermann (1980:35-41) gee 'n volledige uiteensetting van die tipiese elemente wat hierdie meesterverhaal van klag in die teenwoordigheid van God kan bevat:

- Die aanroep van God

- Die verhaal van klag, wat gewoonlik drie sye het:

- 'n Aanklag teen God

- 'n Klag oor die lyding wat die gemeenskap beleef

- 'n Aanklag oor en teen die vyande

- Herinnering aan God se reddingsdade in die verlede

- Gebede om redding

- God se reaksie op hulle versoeke

- 'n Belofte van lof

\section{Klimaks ('climax')}

As aksie, agtergrond en ontwikkeling suksesvol ineengeweef is, sal dit op 'n skielike insig, 'n plotselinge wete, 'n sogenaamde 'a-ha-oomblik', uitloop. In teologiese taal sou 'n mens hierna as 'n coram-deo-ervaring kon verwys. So 'n klimaks is moeilik om te beskryf, en nóg moeiliker om te bewerkstellig. 'n Mens kan hoogstens ' $n$ lys maak van die elemente wat teenwoordig moet wees vir so 'n 'a-ha-ervaring':

- 'n Sinvolle samevoeging van eeue-oue taal en die kontemporêre

- Die stylvolle benutting van kuns, musiek en estetika

- 'n Getroue uitbeelding van gangbare kultuur

- Aanklank by die eeue-oue, dog intellektueel uitdagend en alternatief

- Verstaanbare simboliek

- Gerusstellende handelinge

In Müller (2001) se oordenking oor terapie, sê hy: 'Both good writing and therapy move on the edges of life, are interested in the essence of life and of relationships. Like the writer, the therapist doesn't bring God in from outside; he or she just discovers God in the writing and in the therapy.' Dieselfde geld die liturgie. Liturgie kan God nie van buite inbring nie; dit kan die deelnemers slegs help om God te ontdek. Daarom moet die liturgie getrou bly aan al die verhale, en die koers aandui, maar moet dit die individuele gelowige terselfdertyd genoeg vryheid bied om God op sy/haar unieke manier te ontdek.

Volgens hierdie benadering word die klimaks in die liturgie nie met ' $n$ oordonderende fanfare bereik nie, maar deur ' $n$ sensitiewe fasilitering van 'n proses wat mense sal help om
God te ontdek. Dit kan selfs gedoen word sonder om die naam van God oorvloedig te gebruik, soos wat liturge geneig is om te doen. Dit is veel doeltreffender om sagkens op die 'edges of life' te beweeg. Dáár maak mense hulle eie preke onder die geklank van die Woord, en in die ruimte wat die liturgie skep.

\section{Einde ('ending')}

Die erediens is deel van 'n groter 'skryfproses' - mense is immers heeltyd besig om hulle lewensverhale te skryf. Hulle stap nie die kerk as onbeskrewe, oop leie binne waarop na hartelus geskryf kan word nie; inteendeel, hulle is almal reeds beskrewe. Hulle luister en beleef met ' $n$ positiewe óf negatiewe reaksie, en gebruik dit om verder aan hulle eie stories te skryf.

Daarom is die seën aan die einde van die erediens, wat inderwaarheid ' $n$ 'wegsending' is, so gepas.

Wat Müller (2001) oor die terapeut sê, is eweneens op die liturg van toepassing: 'To be a therapist, like being a writer, is to be able to dream for and with people.' Lamott (1995) gebruik die beeld van die sandkasteel: 'n Deel van jou sien die volgende brander aankom, en wanhoop, want jy dink die oseaan gaan die sandkasteel platvee.

Another part of us thinks we'll figure out a way to divert the ocean. This is what separates artists from ordinary people: the belief, deep in our hearts, that if we build our castles well enough, somehow the ocean won't wash them away. I think this is a wonderful kind of person to be.

(Lamott 1995:231)

Die liturg tel onder die kunstenaars van die lewe: daardie mense wat ondanks alles steeds hoop; daardie mense wat aanhou om met hulle woorde boodskappe soos sandkastele te bou; daardie mense wat glo dat hulle sandkastele sal bly staan en, ten minste vir so lank as wat dit bly staan, betekenis het. Liturge is gelowige profete wat nie moeg word om mense met die woorde van die Evangelie te konfronteer en in die kunswerke van aanbidding in te nooi nie.

'n Narratiewe benadering tot die liturgie kan ongetwyfeld ' $n$ bydrae tot groter integriteit vir die liturgie lewer. Deur die skeppende beligting en ontginning van die raakpunte tussen die verskillende verhale wat in die liturgie ontmoet, sal erediensgangers die liturgie as ' $\mathrm{n}$ betekenisvolle oomblik te midde van die golwe van die tydsgees ervaar.

\section{LITERATUURVERWYSINGS}

Armstrong, K., 2007, The Bible: A Biography, Atlantic Monthly Press, London.

Brueggemann, W., 1989, Finally Comes the Poet. Daring speech for proclamation, Fortress Press, Minneapolis.

Burger, C., 2005, Ontmoetings met die lewende God, Lux Verbi.BM, Wellington.

Demazure, K. \& Müller, J., 2006, 'Perspectives in support of the narrative turn in pastoral care', Nederduits Gereformeerde Teologiese Tydskrif 47(3\&4), September \& Desember 2006, 410-419.

Gibbs, E. \& Bolger, R.K., 2006, Emerging Churches. Creating Christian Communities in Postmodern Cultures, SPCK, Londen.

Freedman \& Combs, 1996, Narrative Therapy, WW Norton \& Company, New York.

Harvey, D., 1990, The condition of postmodernity, Blackwell, Cambridge, Massachusetts.

Kearney, R., 1998, The Wake of Imagination. Toward a postmodern culture, Routledge, Londen.

Lamott, A., 1995, Bird by Bird, Pantheon, New York.

McCarthy, C., 1994, The Crossing, Picador, Londen.

Müller, J., 2000, Reis-geselskap, Lux Verbi-BM, Wellington.

Müller, J., 2001, 'Therapy as Fiction Writing', Nederduits Gereformeerde Teologiese Tydskrif 42(1\&2), Junie 2001, 6470. 
Nederduitse Gereformeerde Kerk, 2001, Liedboek van die Kerk, NG Kerk-Uitgewers, Wellington.

Polkinghorne, D.E., 1988, Narrative knowing and the human sciences, State University of New York Press, Albany, New York.

Ricoeur, P., 1984, Time and narrative, Volume 1, University of Chicago Press, Chicago.
Scheepers, R., 1998, Koos Prinsloo. Die skrywers en sy geskryfdes, Tafelberg, Kaapstad.

Spong, J.S., 2007, Jesus for the Non-Religious, HarperCollins, New York.

Westermann, C., 1980, The Psalms, Structure, Content E Message, Augsburg Publishing House, Minneapolis. 